\title{
Para além das margens: o Conjunto Habitacional Itararé e as remodela- ções dos espaços urbanos em Teresina (década de 1970) ${ }^{1}$
}

\author{
Claudia Cristina da Silva Fontineles* \\ Marcelo de Sousa Neto**
}

Em tempos de tempestades

Diversas adversidades

Eu me equilibro e requebro É que eu sou tal qual a vara Bamba de bambu-taquara Eu envergo mas não quebro (Lenine, 2011).

Introdução

Um dos maiores riscos do trabalho historiográfico consiste naquilo que Marc Bloch denominou de "obsessão embriogênica", na qual as origens representariam "o começo que explica” (Bloch, 2001, p. 57), num exercício de mera explicação reducionista, que ignora a vitalidade e a insubordinação da história a esquemas previamente definidos. Assim advertidos, reconhecemos os riscos que corremos ao procurar entender como se formou o projeto que consubstanciou a

1 Pesquisa desenvolvida com apoio do Conselho Nacional de Desenvolvimento Científico e Tecnológico (CNPq), Edital Universal.

* Professora Associada da Universidade Federal do Piauí (UFPI), Departamento de História, Programa de Pós-Graduação em História do Brasil (PPGHB) e Programa de Pós-Graduação em Ciência Política (PPGCP). E-mail: cfontinelles@gmail.com.

** Professor Associado da Universidade Estadual do Piauí (UESPI), Coordenação de História, Mestrado Profissional em Ensino de História - ProfHistória. Professor do Programa de Pós-Graduação em História do Brasil (PPGHB-UFPI). E-mail: marcelo@ccm.uespi.br. 
construção de um bairro, como é o caso do texto aqui proposto.

O presente artigo visa discutir como foi planejada e implantada a construção do Conjunto Habitacional Itararé - atualmente denominado de Dirceu Arcoverde -, construído para além das margens do Rio Poti (limite leste de Teresina), fora do perímetro urbano da capital piauiense e voltado a moradias populares, durante a década de 1970 . Este viria a se tornar a região mais populosa da cidade até hoje. Procuramos entender como esse projeto foi gestado e ganhou forma dentro da dinâmica histórica e social excludente que se apresentava à população de baixa renda no período. Discutimos como os desafios que se apresentaram ao cotidiano desses moradores se conectaram às contradiçóes vividas pela sociedade brasileira no recorte temporal da pesquisa. Para tanto, recorremos à análise de fontes documentais e hemerográficas, além de recorrer ao uso de entrevistas orais, realizadas com os primeiros moradores da região, a partir da metodologia da História Oral Temática (Ferreira, 2016; Ferreira, 2012; Alberti, 2010; Amado; Ferreira, 2006; Camargo, 1999; Montenegro, 2001, 2007).

\section{Itararé: entre projetos e implantação}

A primeira referência feita ao Conjunto Habitacional Itararé, na imprensa piauiense, foi na matéria do jornal O Dia de 13 de abril de 1976, que noticiou a visita do entáo governador do estado, Dirceu Mendes Arcoverde, às obras dos Conjuntos São Pedro (66 casas) e Bela Vista (912 casas) - residenciais populares construídos na zona sul da capital. A matéria informava que, ainda naquele ano (1976), seriam "iniciadas a construção de mais de três mil casas, possivelmente no bairro Itararé, para atender a programação que ultrapassa a cinco mil casas populares" (Dirceu..., 1976). 


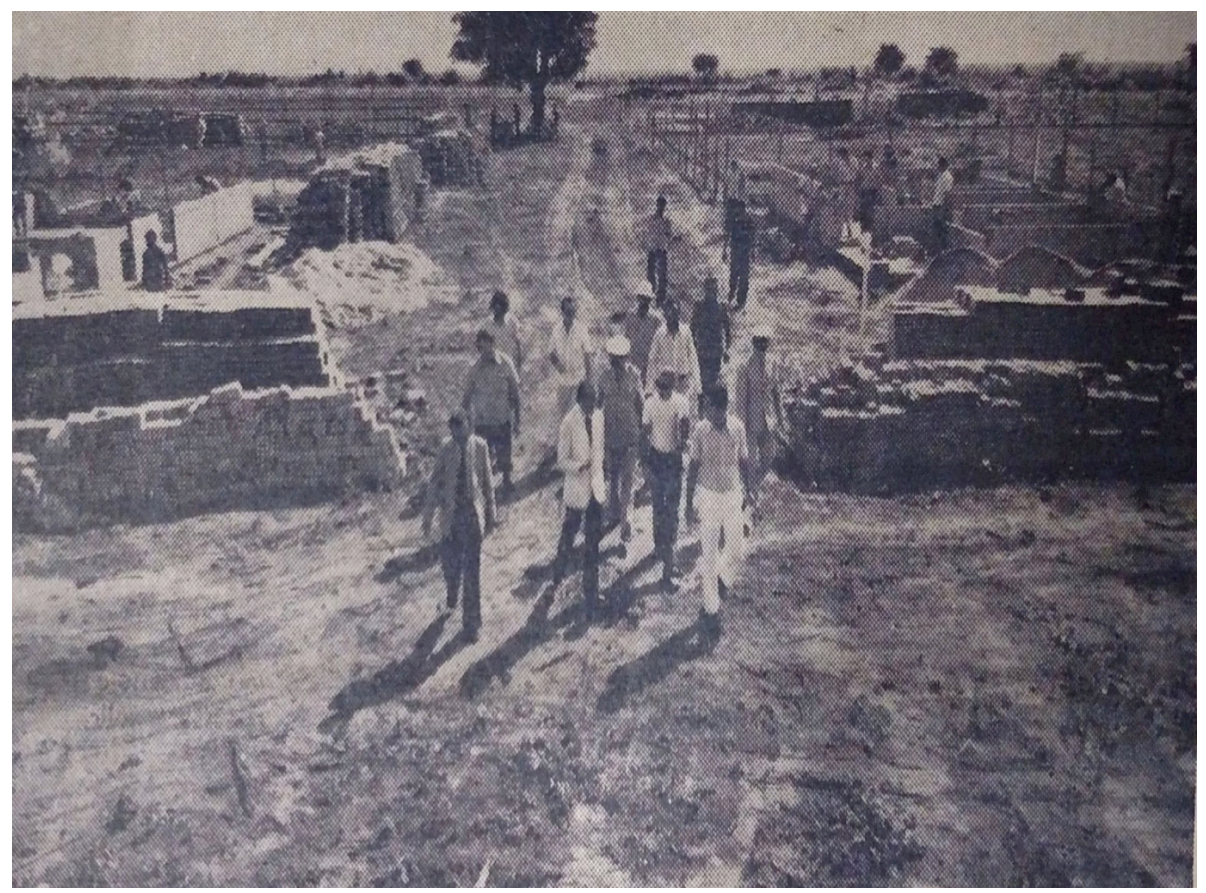

Figura 1 - Visita do governador Dirceu Arcoverde às obras de construção do Conjunto Bela Vista ((Dirceu..., 1976).

É importante esclarecer que o projeto de construção do Itararé já ocupava, há algum tempo, os gabinetes do Palácio de Karnak, sede do governo estadual, que pleiteava, junto ao Banco Nacional de Habitação (BNH), a proposta de construção de 3.040 unidades habitacionais. Esse projeto fora denominado de Conjunto Itararé e teve o contrato de liberação de recursos assinado em 30 de junho de 1976 (Brasil. BNH, 1976). Dessa forma, quando da publicação da matéria, em abril de 1976, o Projeto Conjunto Itararé já se encontrava avançado, inclusive com terreno comprado pelo estado desde fevereiro do mesmo ano, pago com recursos de adiantamento previamente liberados pelo $\mathrm{BNH}$.

Contudo, é preciso entender a configuração histórica vivida por essa administração estadual para compreender os caminhos percorridos até a construção desse residencial. Logo no início de seu governo, Dirceu Arcoverde enfrentou séria crise financeira vivenciada pela política habitacional do estado, decorrente, em grande medida, do declínio do que fora propagado pelo governo autoritário, em nível nacional, como "Milagre Econômico". O que naufragou e reverberou diretamente nos cenários estaduais, sobretudo com o crescimento das desigualdades sociais e do alastramento da pobreza. Esse declínio despertou a atenção no cenário político local no período, como a declaração do deputado estadual Carlos Augusto ao se revelar preocupado com a inadimplência de mutuários da Companhia de Habitação do Piauí (COHAB-PI): 
Espero agora que desapareçam os inúmeros problemas causados aos moradores das mais de três mil casas construídas em Teresina pela COHAB. É um eterno problema que todos os moradores destas casas, que deixam por motivos alheios as suas vontades, acredito, suas mensalidades em atraso. (Augusto, 1975).

Pela declaração, é válido afirmar que o atraso no pagamento das mensalidades pelos mutuários do bairro era corriqueiro, a ponto de gerar o pronunciamento do legislador estadual "como um eterno problema". Dentre as medidas destacadas pelo deputado, encontra-se a renegociação de débitos entre o Governo do Piauí e o BNH. Assim, a liberação de novos recursos para financiamento de projetos habitacionais somente foi possível por meio de acordo firmado entre o banco e o governo do Piauí, considerando que o estado se encontrava em moratória devido aos atrasos assumidos com financiamentos anteriores, notadamente os contraídos para a construção de outros residenciais em Teresina, como a Tabuleta, São Raimundo, Primavera I, Monte Castelo e Parque Piauí entre os anos de 1966 e 1968. Desse modo, em 1975, o governo do estado refinanciou a dívida existente, pagando Cr\$1.500.000,00 (um milhão e quinhentos mil cruzeiros) e parcelando o saldo devedor de Cr\$30.000.000,00 (trinta milhóes de cruzeiros) em 360 meses. Recuperado o crédito para o financiamento de novos projetos, o governo do estado, por meio da COHAB-PI, apresentou novas propostas de conjuntos residenciais com custos mais baixos, nas quais estava a do Projeto "Conjunto Itararé".

Como observa Roberto Lobato Corrêa (2002), será o uso que se atribui à terra que definirá a organização do espaço urbano, pois esta resulta da interferência de vários fatores em constante movimento, em um processo de construção e de reconstrução da cidade. Em relação ao terreno onde o Conjunto foi construído, a documentação consultada indica que ele foi comprado pelo governo do estado, estando "situado no lugar São Raimundo, data covas no município de Teresina, na zona rural, próximo ao Contorno Rodoviário e Terminal de Petróleo" (Brasil. BNH. 1976), composto de seis glebas ${ }^{2}$ que perfaziam um total de $1.115 .000,00$ $\mathrm{m}^{2}$ (um milhão, cento e quinze mil metros quadrados). O terreno pertencia a Clemente Linhares da Silveira, Maurício Camilo da Silveira, Maria José da Silveira, Maria Célia da Silveira Vieira, Ferdinand Silveira e seus respectivos cônjuges, adquirido pelo Governo do estado em 18 de fevereiro de 1976 pelo valor de Cr\$ 3.465.000,00 (três milhóes, quatrocentos sessenta e cinco mil cruzeiros), com recursos antecipados pelo BNH e previstos pelo Projeto (Brasil. BNH. 1976).

O nome Itararé, herdado pelo Conjunto desde o projeto, relaciona-se ao nome de uma fazenda pertencente a Pedro de Almendra Freitas - governador do estado entre os anos de 1951 e 1955 -, localizada no bairro São Cristóvão, na re-

2 Podemos definir "Gleba" como área de terreno que ainda não foi objeto de parcelamento regular. Após o registro do parcelamento, a gleba deixa de existir juridicamente, dando lugar aos lotes e às áreas públicas dela decorrentes. 
giấo leste ${ }^{3}$ da capital. Onde foi construído, em 1973, durante a administração do governador Alberto Tavares Silva, o Terminal de Petróleo de Teresina. Isso atraiu o interesse do poder público pela regiáo.

O habitacional, como imagem significativa da cidade, traz, em sua criação, a representação coletiva do real criado, que, por sua vez, corresponde a uma infinidade de outras cidades vividas e imaginadas por quem nelas vive, um verdadeiro palimpsesto, a exemplo do que observa Sandra Pesavento (2007). No caso estudado, a cidade ganha múltiplas versôes construídas por seus usuários, inserida no turbilhão de transformaçóes propostas pelo discurso modernizador da época, que propunha afastar a população empobrecida para fora da cidade como uma forma de negar qualquer imagem que contrariasse o discurso oficial de prosperidade propagado. Dessa forma, concorda-se com Ana Fani Carlos, quando ela informa que a fragmentação dos espaços urbanos "também revela a hierarquização dos lugares e pessoas" (Carlos, 2001, p. 27), segregando a morfologia espacial e social.

O novo residencial representava parte do espaço urbano segregado, que alterava profundamente a organizaçáo espacial e social da cidade ao separar pessoas, escamoteando a solução do problema de acesso à moradia ao entregar as casas sem a infraestrutura urbana primária para a implantação de uma moradia salubre e segura. O Conjunto Itararé teve suas obras iniciadas ainda no ano de 1976. Em reportagem realizada no mês de julho daquele ano, o jornal $O$ Dia apresentava como estavam as etapas da obra:

Até o final deste mês [junho de 1976] será feito julgamento da concorrência visando a construção das 840 casas do Conjunto Itararé, no bairro São Cristóvão, como a primeira etapa de um total de 3 mil e 40 unidades habitacionais. A construção do Conjunto prevê três etapas, conforme as informaçôes do diretor. Ainda no bairro Itararé será construída [sic] as casas embrião com apenas três cômodos que podem ser ampliados de acordo com as possibilidades e o poder aquisitivo dos compradores. (Itararé..., 1976).

A matéria reconhece a existência de "casas-embriáo" que, segundo o jornal, teriam três cômodos e poderiam ser aumentadas pelos moradores. Conforme as entrevistas com os moradores, estas eram os modelos maiores - denominadas de tipo "A" -, pelas quais se pagava a maior prestação, e não as menores como fazia supor o texto jornalístico. Sob a perspectiva do jornal, supunha-se que os outros modelos seriam mais amplos e mais bem estruturados, o que diverge do que indicam os moradores e os documentos encontrados na COHAB-PI. A concorrência

3 A regiáo anteriormente classificada pela prefeitura de Teresina como Zona Leste ganhou a reclassificação como Zona Sudeste através das Leis n. 2.960 e n. 2.965 de 26 de dezembro de 2000, que dividiram as áreas de atuação da Prefeitura de Teresina em quatro áreas urbanas: Centro-Norte, Sul, Leste e Sudeste. Estas, por sua vez, ficaram sob responsabilidade administrativa das: Superintendência de Desenvolvimento Urbano Centro-Norte, Superintendência de Desenvolvimento Urbano Sul, Superintendência de Desenvolvimento Urbano Leste, Superintendência de Desenvolvimento Urbano Sudeste, esta última englobando a região do "Grande Dirceu". 
pública destacada pela matéria levou um pouco mais de tempo para se iniciar, chegando a termo apenas em 27 de dezembro de 1976, com a assinatura do contrato de empreitada com a empresa vencedora para construção das primeiras 600 unidades habitacionais do $1^{\circ}$ Setor do Conjunto, pelo montante de 74.496,21 UPC (Unidades Padrão de Capital), ou Cr\$ 12.539.946,00 (Brasil. BNH. 1976).

No período em que o projeto Itararé foi apresentado pelo governo do estado, no âmbito nacional, os projetos aprovados pelo BNH deslocavam-se para áreas mais distantes dos centros urbanos à procura de terrenos mais baratos. Reduzia-se progressivamente a área construída e a qualidade das edificaçóes como forma de viabilizar os empreendimentos, baixando os custos de construção, além de possibilitar o retorno dos valores aplicados. Os locais escolhidos, por seu custo de edificação, em geral, eram distantes dos centros e sem qualquer infraestrutura ou equipamento urbano. Isto causava sérios problemas para os moradores e para os poderes públicos municipais e os obrigava a considerar a possibilidade de oferta de serviços básicos a esses locais (Lorenzetti, 2014), inclusive no processo de construção do Conjunto Itararé.

Assim, a Companhia de Habitação do estado determinou três modelos de plantas baixas para edificar as casas, com áreas úteis distintas, definidas em conformidade com a renda familiar dos moradores, "feitas de alvenaria, cobertas de telhas e caibro de madeira redonda" (Itararé.... O Dia, 20 ago. 1977, p. 6). Como pode ser observado na imagem a seguir:

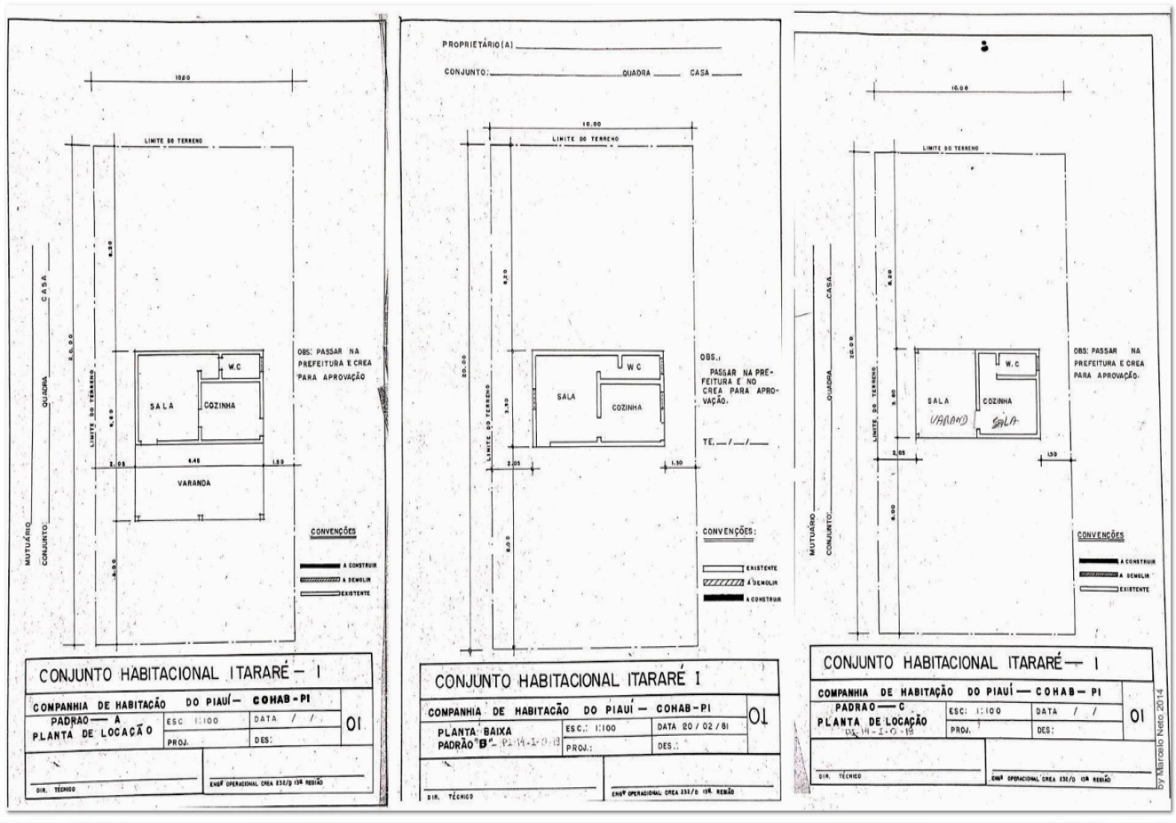

Figura 2 - Planta baixa dos modelos das casas construídas no conjunto itararé (Fonte: Piauí. COHAB. Certidão de construção do bairro Itararé. Teresina: COHAB-PI, 1981.). 
O primeiro elemento que se sobressai na Certidão de construção do bairro é seu nome originário: Itararé. Além disso, pode ser observado, à esquerda do documento, a especificação do modelo Tipo "A" e, ao centro, a do modelo Tipo "B", diferenciados pela existência ou não do que foi nomeado "varanda" (a construção de uma área aberta, coberta de telha, sem paredes). À direita, pode ser vista a especificaçáo do modelo Tipo "C", o menor dos três modelos, resumido a um único cômodo, banheiro e varanda lateral.

Torna-se oportuno, então, discutir um pouco mais sobre as casas construídas, pois foram estas as responsáveis pelos primeiros laços afetivos dos moradores com o Conjunto, em experiências por vezes traumáticas. Porém que, como ressalta Raquel Rolnik (2004), contêm parte das vivências de seus moradores, denotando o mundo em que viveram.

Com reduzidas áreas de construção, as casas eram muito pequenas para acomodar as famílias que chegavam, no geral, numerosas. Além disso, comparada a outro conjunto popular, o Parque Piauí, situado na zona sul da cidade, como destaca um periódico da época, "não são tão confortáveis como aquelas da ampliação do Parque Piauí. São bem mais modestas, mas caracterizam-se principalmente por um preço mais baixo" (Itararé... O Dia, 20 ago. 1977, p. 6). A fragilidade dessas moradias foi denunciada por seus moradores, embora sob a forma irônica e bem-humorada, como narrado pela moradora Maria da Conceição:

Quando veio morar, o pessoal deu até assim um apelidozinho: um ovo. Era uma casa pequena, muito pequena, só tinha... uma sala, um banheiro, uma cozinha e uma área aberta. A gente fechava e fazia um quarto ou uma sala, porque eram dois tipos de casas: um tipo "A" e um tipo "B". A nossa era tipo "A". (Maria da Conceição, 2010).

A declaração da moradora permite perceber que a proposta de construção das casas não atendia às necessidades de seus moradores, evidenciando ainda que a permanência no residencial dava-se por fatores alheios ao seu desejo. O tamanho das casas - comparadas a ovos, "casa pequena, muito pequena" - era uma constante nos relatos dos primeiros moradores. Mesmo assim, na fala da moradora, sobressai-se o orgulho pelo distintivo de ter sido contemplada com uma casa do Tipo "A", que contava com uma pequena área aberta, coberta em sua parte da frente, diferenciando-se das menores obtidas por outros moradores, com renda inferior à de seu núcleo familiar. Essas distinçôes no tipo de casas e nas prestaçóes também foram ressaltadas por outros moradores. A senhora Rosa Maria da Costa Alves, por exemplo, informa que sua família havia recebido uma casa tipo "B", mas foi trocada pela $C O H A B$ por uma do tipo "A", que era um pouco maior, todavia, com uma prestação também mais elevada. Considerava que o modelo inicial não comportava sua família:

Ganhei uma tipo "B”, mas não cabia meus filhos [...] Esta daqui (tipo 
"A") era pros que tinham melhor poder aquisitivo. [...] Esta que eu moro era a última livre. Aí a mulher da COHAB falou: "Tem essa tipo "A", mas você vai ter que pagar mais". Eu disse "Tudo bem”, eu já trabalhava na lavanderia, né? (Rosa Maria da Costa Alves, 2017). ${ }^{4}$

Essas diferenciações nos modelos das moradias e nos preços de suas prestaçóes indicam que, embora fosse um residencial voltado prioritariamente para moradores de baixa renda, com forte vulnerabilidade social e que enfrentavam muitas dificuldades e restrições em relação ao acesso à moradia - muitos deles oriundos de moradias irregulares em diferentes regiôes da cidade -; havia distinções sociais entre os próprios moradores, expressadas nos três tipos de casas construídas e nos valores pagos para ter acesso a elas. Isto, inclusive, é muito destacado pelos primeiros moradores, que recordam dessa diferenciação como um elemento que gerava certa distinção entre os moradores. Os que residiam nas casas tipo "A" costumam dar ênfase ao fato de pagarem mais, enquanto os moradores dos tipos "B" e "C" salientam um certo pesar por não terem conseguido casa do modelo maior.

No relato da senhora Maria da Conceição, ela informa haver dois modelos de casa, não se referindo ao tipo "C", a menor entre os três modelos. Entretanto, mesmo que este não tenha sido um tipo de construção mencionado pela moradora, o Tipo "C" existiu, sendo o menor número de casas construídas - apenas três quadras -, talvez por isso tenha sido ignorado no relato da moradora. Em regra, esse tipo de casa deveria ser adquirido pelas famílias que atendiam ao perfil estabelecido pela COHAB-PI, mas que possuíssem renda inferior à dos que pleiteavam os demais modelos. Porém, os moradores destacaram que houve muitas exceções, as mais mencionadas foram a redistribuição em virtude do número extenso de filhos e a existência de mutuários fora do perfil social estabelecido pela companhia habitacional. Alguns moradores chegavam a atribuir essa última exceção a favorecimentos conseguidos junto a políticos locais.

A respeito da lacuna presente no relato da senhora Maria da Conceição, ela não compromete a validade de seu relato, mas ajuda a endossar o que propóe Gwyn Prins acerca do trabalho com fontes orais. Segundo este,

A questão é que o relacionamento entre as fontes escritas e orais não é aquele da prima-dona e de sua substituta: quando a escrita falha, a tradição sobe ao palco. Isso está errado. As fontes orais corrigem as outras perspectivas, assim como as outras perspectivas as corrigem. (Prins, 1992,

4 Imigrou para a cidade de Teresina em fevereiro de 1959, vindo grávida da cidade de Viçosa (CE), em decorrência da Seca de 1958. Na oportunidade da entrevista, contava com 84 anos de idade e residia na mesma casa recebida em 1977. A viúva, na passagem, refere-se ao trabalho que desenvolveu na Lavanderia Pública do estado, situada no bairro Ilhotas, que, junto à pensão de um salário mínimo que recebia do esposo, morto em um acidente de trabalho na Usina Santana, foi a renda que a fez criar seus seis filhos sozinha, longe de sua família que havia permanecido no Ceará. 
p. 166).

Assim, para Prins - perspectiva também compartilhada por esta pesquisa - as fontes orais não se constituem como complementos à fonte escrita, mas como uma fonte valiosa, que possui seus méritos e riscos, e, como as demais, deve ser trabalhada criteriosa e criticamente. Dessa forma, contribuindo para fazer surgir novas possibilidades de análises, como ocorreu nessa pesquisa. Uma dessas possibilidades de análises refere-se ao modelo e à distribuição das unidades habitacionais construídas no Conjunto. Por meio da consulta à documentação, encontramos o contrato celebrado em 30 de junho de 1976 entre o Banco Nacional de Habitação e a Companhia de Habitação do Piauí, que teve o governo do estado como interveniente. No contrato, consta o acerto da construção de 3.040 casas do Conjunto Itararé, com a seguinte distribuição:

\begin{tabular}{|c|c|}
\hline \multicolumn{2}{|l|}{ Padrão TIPO “A” } \\
\hline Da Quadra - 49 a 54 & 120 unidades \\
\hline Da Quadra - 58 a 63 & 120 unidades \\
\hline Da Quadra - 67 a 72 & 120 unidades \\
\hline Da Quadra - 76 a 81 & 120 unidades \\
\hline Da Quadra - 85 a 90 & 120 unidades \\
\hline Da Quadra - 140 a 150 & 192 unidades \\
\hline TOTAL (41 Quadras) & 792 unidades \\
\hline \multicolumn{2}{|l|}{ Padrão TIPO “B” } \\
\hline Da Quadra - 01 a 46 & 1004 unidades \\
\hline Da Quadra - 55 a 57 & 60 unidades \\
\hline Da Quadra - 64 a 66 & 60 unidades \\
\hline Da Quadra - 73 a 75 & 60 unidades \\
\hline Da Quadra - 91 a 139 & 980 unidades \\
\hline E Quadra - 151 & 24 unidades \\
\hline Total (107 quadras) & 2188 unidades \\
\hline \multicolumn{2}{|l|}{ Padrão TIPO “C” } \\
\hline Da Quadra - 82 a 84 & 60 unidades \\
\hline Total (03 quadras) & 60 unidades \\
\hline Total Geral (151 Quadras) & 3040 unidades \\
\hline
\end{tabular}

Quadro 1 - Distribuição das casas do Conjunto Itararé, por quadra e tipo (Fonte: Brasil. BNH. Contrato de empréstimo entre o $\mathrm{BNH}$ e a COHAB-PI, com a interveniência do estado do Piauí [Projeto: Itararé. Objeto: 3040 casas]. Rio de Janeiro, 30 jun. 1976.). 
É importante observar que o modelo mais construído foi o de casas Tipo "B", com 2.188 unidades, seguido pelas casas Tipo "A", com 792 unidades, além das casas Tipo "C". Segundo informam as fontes governamentais, a todos os inscritos como mutuários era exigida comprovação da renda de um salário mínimo por família. Muitos moradores informavam que era exigida essa comprovação durante o cadastro, e que isso era acompanhado por assistentes sociais do município que os encaminhavam à COHAB. Durante a pesquisa, não foi encontrada documentação do poder público esclarecendo como eram estabelecidos e acompanhados esses critérios. Os moradores entrevistados informaram que a maneira mais segura para ter o cadastro aceito era apresentar o registro da renda via carteira de trabalho, embora esse não fosse o único meio, devido ao perfil socioeconômico dos moradores, mas foi o mais destacado. A senhora Maria Neide, por exemplo, declarou:

Eu trabalhava como merendeira nas construçóes e foi com esse dinheiro que eu pagava nossa prestação, mas minha casa é no nome do meu marido porque era ele que trabalhava com carteira assinada. Não me deixaram botar a casa no meu nome. Só por isso consegui concorrer a uma casa aqui, mas eu sabia de gente que conseguiu sem a carteira azul. Eu não sei como, mas conseguiu... talvez tivesse quem ajudasse, né? Eu, como não tinha, nunca fui de andar pedindo favor a ninguém, tinha que mostrar tudo no papel. O bom é que eu não fiquei devendo nada a ninguém, só a Deus, e podia sentar na minha porta de cabeça erguida, sem nenhum político ficar mandando em quem eu votar. (Maria Neide Fontineles, 2014). ${ }^{5}$

No relato da moradora, percebe-se a denúncia da facilitação do acesso às casas do Habitacional por alguns mutuários. Pelas declarações, também é possível reconhecer o orgulho demonstrado pela moradora, que descreve ter vivido as dificuldades e reagido às relaçóes de clientelismo com os políticos da época "de cabeça erguida”, ao não aceitar se sujeitar às formas de apadrinhamentos políticos para conseguir a moradia. Declaraçóes como essa evidenciam as diferentes formas de acesso às casas do Itararé, como tratado anteriormente.

\section{Um mesmo residencial, diferentes regras de acesso}

5 Atualmente aposentada, tinha 61 anos quando foi entrevistada. Ao chegar em Teresina, no início de 1976, a entáo dona de casa passou a trabalhar como vendedora de merenda nas construçóes civis da cidade para ajudar no orçamento familiar, já que o marido trabalhava como ajudante de pedreiro. Ao chegar no novo bairro, passou a conciliar esse ofício com o de vendedora de verduras no mercado instalado no habitacional. Pagará a contribuição previdenciária de maneira autônoma até sua aposentadoria. 
Em sua declaração, Maria Neide deixa claro que havia distinçôes também na maneira de selecionar os moradores, e que isso náo era transparente, nem isonômico. Percebe-se um sentimento de impotência diante das exigências do poder público por parte daqueles que náo dispunham de "interlocutores" políticos que os "ajudassem" na conquista da casa caso náo pudessem comprovar a renda exigida. A declaraçáo também indica uma cadeia de dependência heterodoxa, gerada entre alguns moradores e entes do poder público ou políticos, a partir de critérios pouco transparentes na inscrição e distribuição das moradias. Isso, por sua vez, talvez contribua para entender melhor a relação entre a comunidade que passou a residir lá e alguns grupos partidários, conforme denotado na fala da moradora. Vários outros moradores confirmaram esse tratamento diferenciado quanto à entrega das unidades habitacionais. Segundo eles, muitos candidatos a mutuários traziam outras formas de comprovação que não a apresentação da carteira de trabalho, e toda documentação era apreciada pela Assistência Social da Prefeitura e pelos funcionários da $\mathrm{COHAB}$, no entanto, também existiam casos em que havia denúncias de favores políticos em troca de uma unidade habitacional no Conjunto.

Isso não significa necessariamente que todas as situaçôes tenham sido originárias de favores clientelistas. Há também os moradores que foram dispensados de apresentar comprovação de renda e que nem sequer tiveram que fazer inscrição, dado que suas unidades habitacionais já estavam asseguradas previamente pelas autoridades ao serem removidos de suas antigas habitaçóes. Foi o caso dos moradores que residiam nas proximidades da linha férrea, no bairro Ilhotas, na zona sul de Teresina, como declarou a senhora Rosa Maria. Houve também aqueles que informaram terem recebido "desistências" de casas, em virtude da falta de interessados no residencial, como a senhora Maria Sancho. Quando perguntada se ela havia feito a inscrição para o Conjunto, respondeu que não havia se inscrito e que a casa teria sido "arranjada". Segundo a moradora, isso ocorreu porque: "Na época ninguém queria vim para o Dirceu, dava graças a Deus quando achava alguém que queria. Ninguém queria. Não tinha água, não tinha luz, não tinha transporte, não tinha nada. Ninguém queria. Só vinha quem tinha necessidade mesmo" (Maria Sancho Pereira, 2014). ${ }^{6}$

A falta de alternativa de uma moradia melhor parece ter sido um dos elementos decisivos na distribuição de parte das unidades habitacionais, uma vez que, ao se depararem com a completa falta de estrutura para se instalar, muitos dos primeiros a receber as casas no Conjunto desistiram das residências. A senhora Maria Sancho disse ter se transferido para a regiâo no dia quatorze de janeiro de 1978 , quando muitos moradores já haviam começado a se instalar na região desde julho de 1977. Ela própria afirma ter recebido sua casa em agosto do ano de

6 A aposentada tinha 70 anos na data da entrevista. Mãe de sete filhos biológicos e dois adotivos, é considerada uma das pessoas mais influentes do conjunto habitacional em decorrência das ações profissionais que desenvolvia à frente do Centro Social Urbano, implantado no bairro, e da assessoria que prestava a Francisco Alves e a Irmani Veloso, durante os anos que seguiram à instalaçáo do residencial. 
1977, mas que aguardara, sem êxito, melhorias estruturais no Conjunto. Diante do medo de perder a casa, não teve outro recurso a não ser se transferir para o local no final daquele ano.

Em relação à precária estrutura física das casas, é possível observar uma série de registros jornalísticos que endossam as declaraçóes orais feitas pelos primeiros moradores. A imagem a seguir consta em uma matéria explicitando as casas do tipo "C". No lado esquerdo da fotografia, é possível identificar a área lateral coberta e sem paredes, que constava no modelo original, semelhante ao descrito na planta baixa do Conjunto.

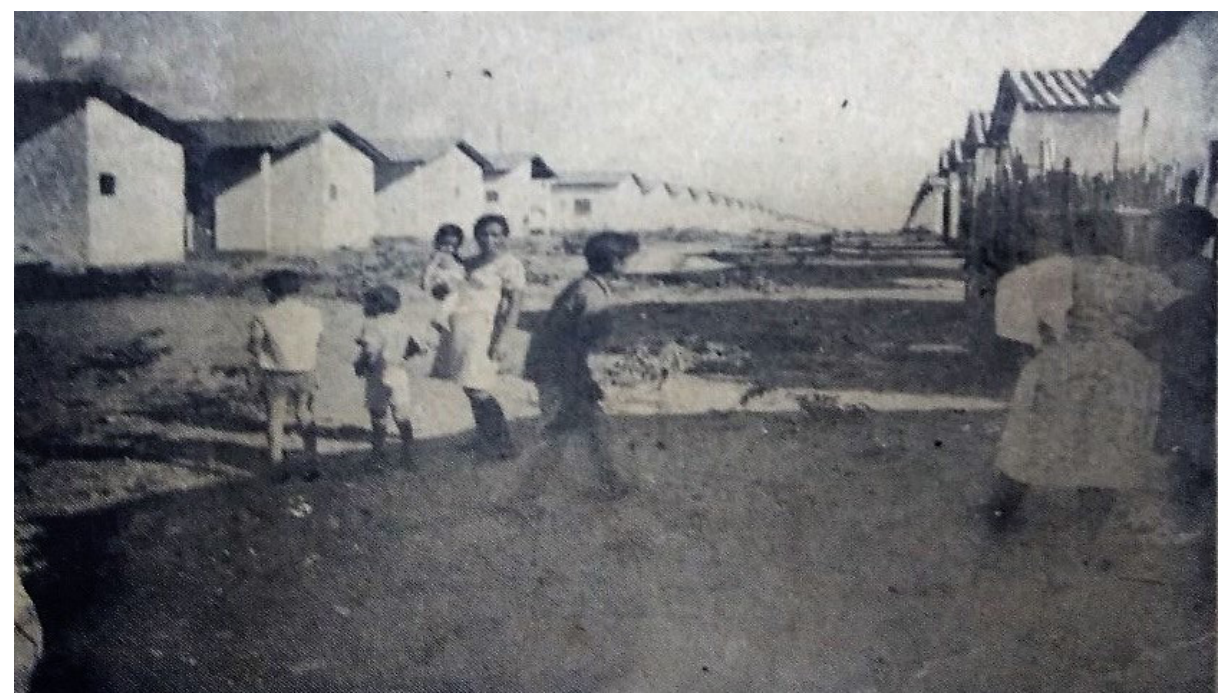

Figura 3 - Primeiros moradores do Conjunto Itararé, 1977 (Itararé..., 1977).

A fotografia utilizada no periódico local permite fazer algumas inferências acerca de alguns desafios enfrentados pelos primeiros moradores do bairro Itararé, notadamente em relação à infraestrutura do Conjunto, com ruas sem calçamento e sem energia elétrica. $\mathrm{O}$ que pode ser percebido, na imagem, pela ausência de postes da companhia de eletricidade, que só vieram a ser implantados no final do ano de 1977, meses após a instalação dos moradores. Temos consciência de que a fotografia não é um retrato do real, mas sim uma linguagem semiótica que traduz interesses de quem a produz, a publica e a consome. O fotógrafo do jornal, por exemplo, fez questão de registrar uma senhora com muitas crianças em seu entorno, como se quisesse fixar para os leitores do periódico, por meio da foto, o perfil social dos moradores do bairro: pessoas com baixa renda e com famílias extensas. Esse perfil é confirmado pelas demais fontes a que tivemos acesso nesta pesquisa.

$\mathrm{Na}$ matéria jornalística do jornal O Dia intitulada Itararé: uma cidade está se erguendo em Teresina, aparecem cercas rústicas, feitas com talos de coco, nos terrenos limítrofes entre as casas. A existência das cercas tanto pode significar o desejo por privacidade - pois, como defendem Michel de Certeau e Luce Giard, 
ao pesquisar sobre a importância do bairro na história, "este território privado, é preciso protegê-lo dos olhares indiscretos" (Certeau; Giard, 2005, p. 203) -, quanto pode significar que, mesmo no início do estabelecimento das famílias no habitacional, em agosto de 1977 (mês da matéria), já havia a preocupação entre os moradores para com a privacidade e a segurança da família.

Essas cercas em madeira, ao invés de muros de alvenaria, evidenciam ainda a baixa renda dos habitantes, que os impossibilitava de arcar com os custos deste tipo de construção. Podem também ter sido uma reação da população à intensa campanha governamental e jornalística sobre o estereótipo negativo construído acerca das pessoas que se mudavam para o novo Conjunto. Aliás, essa região passou a ocupar bastante as páginas dos jornais desde sua formação. O Itararé ficou estigmatizado, no período, como uma região pobre, distante e violenta. Os primeiros moradores contestam, em seus relatos, esse último rótulo, pois informam, com muita regularidade, o hábito de transitarem a pé, à noite, para se deslocar, em oposiçáo a outros bairros ou ao centro da capital, sem serem importunados por qualquer intervenção fortuita de violência urbana. Esse tipo de deslocamento ocorria em decorrência da irregularidade do atendimento dos meios de transporte coletivo na região.

Há ainda um outro dado intrigante suscitado pela fotografia: o vestuário das mulheres e das crianças está incompatível com o usado pelos moradores do bairro em seu cotidiano, por exemplo, com crianças de bermudas e camisas. Quando perguntados sobre isso, a partir da exposição da imagem do jornal, os moradores consultados declararam não ser comum as crianças e mulheres do bairro, no seu dia-a-dia, vestirem-se como as da fotografia, exceto quando se ia à escola, à igreja, a algum consultório médico ou a outro evento social. Essa divergência pode sugerir que as pessoas fotografadas se dirigiam, na ocasião da captura da imagem, a algum evento ou lugar especial no bairro, ou talvez até mesmo que se tenham vestido assim para registro imagético para a matéria em apreço.

Nesse caso, o ângulo da fotografia, ao destacar uma casa tipo "C", pode pretender enfatizar justamente o quadro de maior carência na região, uma vez que esse tipo de moradia ocupava apenas três quarteiróes, e, mesmo assim, foi o escolhido para ser retratado na matéria. Esse nosso exercício analítico só confirma que a fotografia não pode ser entendida como o real, mas como uma representação desse real (Kossoy, 2001). Nos relatos orais, os moradores destacaram que, cotidianamente, adultos e crianças trajavam-se de forma simples, o que pode ser notado em diferentes coberturas jornalísticas, como a que segue: 


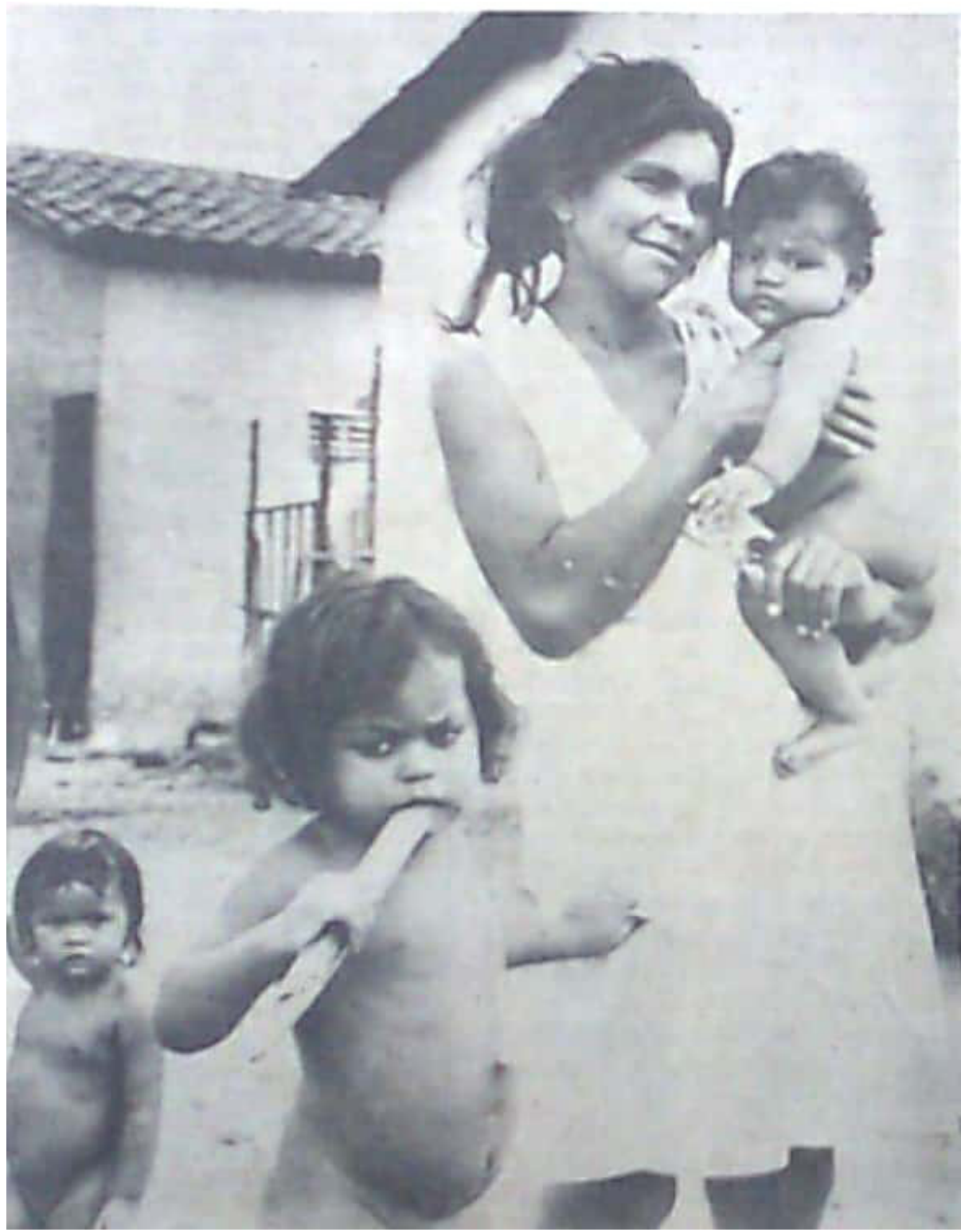

Figura 4 - Moradores do Conjunto Itararé - 1979 (Arcoverde..., 1979)

As matérias jornalísticas pretendiam dar destaque ao quadro de carência apresentado na região. Era muito comum nelas aparecerem crianças nuas e descalças, em franca exposiçáo do quadro de carência enfrentado no cotidiano por 
essa população. No caso piauiense, as coberturas jornalísticas apresentavam jovens mães que muito se assemelhavam às mulheres pobres descritas por João Manuel Cardoso de Mello e Fernando Novais. Esses historiadores, ao tratar sobre o quadro de pobreza do Brasil durante o Regime Militar, declararam que "as mulheres, umas velhas aos trinta anos" (Mello; Novais, 2004, p. 578), punham em evidência o envelhecimento precoce que acometia a população pobre no período.

A reportagem destaca uma jovem, que sorria com um semblante sereno e amistoso, possivelmente a máe das crianças, que parecia ter bem menos do que os trinta anos referidos no texto de Mello e Novais. Mas que, nem por isso, estava fora do quadro social excludente que impelia suas contemporâneas ao envelhecimento precoce. A cena parecia querer confirmar a descrição feita pelos historiadores, ao tratar do cenário nacional do período: "Todos descalços, um ou outro possuindo uma bota ou uma alpargata, as crianças nuas ou só de calçãozinho, barrigudas [...]" (Mello; Novais, 2004, p. 577). Essas dificuldades foram algumas entre as muitas enfrentadas por esses moradores. Seus relatos orais nos permitiram contactar vários fragmentos dessa história recente de Teresina, revelando a importância e a validade da história do tempo presente para o conhecimento histórico (Dosse, 2012; Bédarida, 2006; Rioux, 1999)

A partir dos relatos dos moradores, observa-se que, no cenário teresinense, o primeiro desafio era ser contemplado com uma das unidades do novo residencial, visto que muitos candidatos náo conseguiam comprovar renda, como o exigido; outro era conseguir transferir-se com sua família e mobília para o novo bairro. Em relação à instalação dos habitantes, apesar de a Prefeitura informar que auxiliaria o deslocamento dos mutuários, os moradores que colaboraram ${ }^{7} \mathrm{com}$ esta pesquisa afirmaram não ter recebido apoio algum e descreveram que os custos com o pagamento de veículo oneravam e dificultavam ainda mais sua transferência para a região. Alguns declararam que isso chegava a retardar a ida para a unidade habitacional obtida.

Conforme os documentos oficiais, o direito de acesso às casas era realizado por meio de inscriçóes, análise socioeconômica e sorteio de unidades pela COHAB-PI. Muitos candidatos que pleiteavam as casas não conseguiam atender à exigência da renda, enquanto alguns, que a atendiam, declinaram para se instalarem em outros conjuntos habitacionais com melhores estruturas físicas e mais próximas do centro da cidade. É o caso dos conjuntos Parque Piauí, Bela Vista e Saci ${ }^{8}$, como ressaltou uma das primeiras moradoras do Conjunto, a senhora Maria do Amparo Santos Silva:

Quando surgiu esse conjunto aqui eu não me inscrevi no momento, aí depois de muito tempo [...] as casas já estavam feitas, como ninguém queria,

7 Denominamos os entrevistados de "colaboradores", assim como orienta Paul Thompson. In.: TOMPSON, Paul. A voz do passado: história oral. São Paulo: Paz e Terra, 2002. 3. ed.

8 Esses conjuntos foram inaugurados, respectivamente, em 1968, 1976 e 1979. 
porque era muito longe, não tinha estrutura nenhuma, sobraram casas e aí me deram uma inscrição e eu só fiz terminar de preencher lá meus dados, aí fui sorteada numa casa. (Maria do Amparo Santos Silva, 2010). ${ }^{9}$

Vários moradores destacaram a grande distância do bairro em relação ao centro da cidade e a infraestrutura deficitária do local como motivos para o reduzido interesse por ocupar as casas, o que justificaria a sobra de unidades, corroborando o que já fora dito por outros moradores. Essa situação se assemelha ao descrito na pesquisa de Maria Sílvia Barros Lorenzetti, que analisa como a distância em relação aos locais de trabalho e a precariedade dos serviços disponíveis nos conjuntos populares funcionaram como fatores fundamentais para a recusa da população em ocupar as habitaçóes financiadas pelo $\mathrm{BNH}$ em diferentes regióes brasileiras (Lorenzetti, 2001). Essa também foi a impressão que a senhora Maria Sancho Pereira teve sobre o Itararé. Segundo ela, mesmo com casas já prontas, o residencial não conseguia atrair moradores. A moradora, funcionária aposentada da Secretaria de Trabalho e Ação Social, líder comunitária e uma das primeiras moradoras da região. Ela relembra que, em novembro de 1977, "eram 14 famílias no final de [19]77, eram poucos moradores" (Maria Sancho Pereira, 2014).

Entre algumas dessas famílias, estavam as cadastradas pela "Operação João de Barro", na zona leste da cidade, como a família da senhora Maria Neide. Ela relembra a resistência que os moradores enfrentaram para ir morar no Itararé, informa que: "muitos vinham e logo iam embora. Vendiam as casas seja por quanto fosse. Tinham aqueles que vinham olhar e quando viam a situação, as ruas sem calçamento, sem transporte, tudo coberto de poeira, tinha deles que desistiam de vir" (Maria Neide Fontineles, 2014).

Essa é mais uma declaração que póe em evidência o quadro de carência infraestrutural enfrentado pelo novo habitacional, colidindo diretamente com as declaraçóes oficiais de governantes e entes públicos no período, divulgadas pelos periódicos. Por sua vez, estes, em sua maioria, confirmavam o quadro de fragilidade estrutural ao qual estava sujeita essa população. Esse desinteresse pela região, entretanto, começou a mudar a partir de 1978, quando o Itararé passou a receber um incremento populacional maior devido aos muitos moradores transferidos de áreas irregulares da cidade, que encontraram no Conjunto uma opçáo viável de moradia regular. Essas transferências continuavam integrando o projeto institucional de deslocamento das famílias das moradias irregulares na zona urbana de Teresina coordenado pela prefeitura e pelo estado. Isto é confirmado pela declaração da senhora Maria Sancho:

No final do ano, os prazos deles tinham terminado [moradores irregulares]. Eles tinham que sair dos locais que estavam de qualquer maneira, aí

9 Servidora aposentada pela Escola Odylo de Brito Ramos, casada, mãe de 4 filhos. Moradora do Itararé desde 1978, chegou ao conjunto vindo do bairro São Cristóvão para trabalhar na escola. Tinha, à época da entrevista, 57 anos. 
correu todo mundo com medo, e eles tinham que ir. Alguns foram para ficar, outros foram só de passagem. Chegavam e vendiam a casa para outro, ou deixavam a casa. [...] Aí em [19]78, arrochou, chegou muita gente. O Chico Alves trouxe muita gente, nos caminhóes da Secretaria do Trabalho. (Maria Sancho Pereira, 2014, grifos nossos).

No seu relato, a senhora Maria Sancho confirma o caráter coercitivo e a ativa presença do Estado na transferência dos moradores, retirados de forma compulsória de suas antigas moradias. Confirma também que as unidades recebidas não atendiam às necessidades mais básicas deles, além de lhes fazer contrair o débito das mensalidades de um financiamento imobiliário que nem todos conseguiam pagar, como é declarado à exaustão pelos entrevistados. Isso lhes causava um dilema: ficar sem moradia que fosse regular/irregular, mas próxima de seus locais de trabalho e estudo, ou ir para um Conjunto com uma série de carências infraestruturais, mas com situaçáo regularizada junto ao poder público.

A questão da distância e da dificuldade de acesso ao transporte coletivo é recorrente nas declaraçôes dos moradores e dos servidores públicos que trabalharam lá nos anos iniciais de sua implantação. A professora aposentada, Inês Pereira dos Santos, que construiu carreira profissional como professora e como diretora em escolas do Itararé, nelas trabalhando desde sua inauguração, salienta as dificuldades enfrentadas pelos moradores. Quando perguntada sobre o perfil da clientela atendida pelas primeiras escolas da rede estadual na regiáo, a senhora Inês declarou:

Dos pais, eu, a gente, observava que eram pessoas pobres, que trabalhavam, vinham a pé, a gente naquela época era difícil transporte, né? Tinham muitos que vinham trabalhar aqui no centro, vinham até caminhando porque achavam a demora muito grande dos onibus, eles vinham caminhando; outros por falta mesmo de dinheiro. A gente via que eram pessoas pobres que... a gente observa até pela distribuição das casas do conjunto, era mais assim: filhos de domésticas que trabalhavam aqui no centro nas casas do pessoal rico, considerado naquela época. Tinham comerciantes também, mas comerciantes pobres, pequeno, pequeno comerciante. (Inês Pereira dos Santos, 2013).

Uma das primeiras moradoras do Conjunto, a senhora Maria Dalva, corrobora essa declaração da professora quanto à dificuldade do acesso ao Conjunto. Segundo ela, além de não haver sistema de transporte coletivo, nem sequer os transportes particulares conseguiam transitar no início:

Não tinha poste, não tinha calçamento. Só tinha as ruazinhas cheias de toco, cheias de mato ainda, aquele mato pequeno, sabe? Mas, tudo com aqueles tocos no meio. Não entrava carro, não entrava nada. Os carros que entravam eram os caminhóes deixando... porque já estava tudo bati- 
dinho, mas tinha aqueles tocos, era só o que tinha. (Maria Dalva Damião, 2017). ${ }^{10}$

Os "tocos" mencionados eram os indícios do desbravamento urbano gerado na regiáo, o que evidencia o desmatamento gerado para dar acesso à construção do habitacional. Em uma localidade distante da zona urbanizada da capital, é mais uma demonstração da distância do Itararé em relação ao centro de Teresina.

\section{A expansão dos serviços públicos e os novos moradores}

Ao se referir ao começo da ocupação do Conjunto, mais especificamente, sobre as famílias que puseram seus filhos para estudar na Unidade Escolar Odylo de Brito Ramos que ela dirigiu, a professora Inês Pereira acrescenta que a maioria era composta por:

Trabalhador da construção civil, aquele pessoal que a gente via e observava com aquela farda tudo ali na frente da escola, que era a avenida principal [...]. Não tinha calçamento, não tinha asfalto, a gente via eles passando de bicicleta, pra cá pro centro. A carência era marcante. A gente sentia logo, né, que era uma comunidade carente. (Inês Pereira dos Santos, 2013, grifos nossos).

A professora que, durante a entrevista, concedida no ano de 2013, residia no centro de Teresina, evidencia sua admiração a resiliência dos primeiros moradores do Itararé. Eles se deslocavam a pé ou de bicicleta para trabalhar no centro da cidade, percorrendo um trajeto de aproximadamente dez quilômetros para chegar ao serviço, o mesmo para retornar a suas moradias. Ela destaca que isso se dava por diferentes motivos, entre eles, a falta de recursos financeiros e a carência no sistema de transporte coletivo que atendia aquela regiáo. Ela mesma informou que passava o dia inteiro na escola em que trabalhava porque o sistema de transporte e a distância a impediam de ir almoçar em casa - o que era uma prática muito comum entre os trabalhadores teresinenses na década de 1970. Segundo a professora, esse sacrifício era comum entre aqueles que trabalhavam na região, o que fez com que muitos conhecidos seus passassem a residir no próprio Conjunto, como ocorreu com vários professores e funcionários públicos.

Nesse sentido, esses relatos informam que uma significativa parcela dos moradores do novo Conjunto era formada por operários da construção civil e por empregadas domésticas. Confirmamos estudos de João Manuel de Mello e Fernando Novais, quando declaram que "a entrada do migrante rural no mercado de

10 Nascida em 1957, casada, mãe de quatro filhos. Residia em uma moradia irregular no bairro São Cristóvão antes de receber a unidade no Itararé. 
trabalho se dá, em geral, para os homens, na construção civil, e, para as mulheres, nos serviços domésticos" (Mello; Novais, 2004, p. 598), em muitos casos, sendo incorporados em trabalhos informais e irregulares, nessas ou em outras funçóes.

Outro dado importante apresentado pela professora foi a ampliação da rede de funcionários públicos trabalhando na regiáo, muitos dos quais se tornaram moradores do Conjunto, o que indica a formação de uma estrutura administrativa que passou a atender essa zona urbana. Essa ampliação na rede de serviços públicos em muito se deveu à expansão da rede de atendimento escolar no bairro. $\mathrm{O}$ que ratifica outra dimensão da pesquisa de Mello e Novais, que, em linhas gerais, concluíram, a despeito das dificuldades enfrentadas e da irregularidade na cobertura de atendimento, que "muitos dos trabalhadores comuns puderam ainda colocar seus filhos em escolas públicas [...]" (Mello; Novais, 2004, p. 621). Isto é notado pelo crescimento no número de estudantes matriculados entre as décadas de 1960 a 1980: em 1980, havia 17,7 milhões de estudantes matriculados no país, contra 6,5 milhóes da década de 1960. Ainda assim, os pesquisadores advertem que o ensino era de péssima qualidade e marcado pela exclusão e evasão:

De cada cem alunos, apenas 37 chegavam à quarta série, e só dezoito, à oitava série: os mais pobres estavam muito sujeitos à repetência e tinham de abandonar a escola quando chegava a hora de trabalhar. Por força do crescimento do sistema escolar, multiplicou-se o número de professores, merendeiras, serventes, etc. (Mello; Novais, 2004, p. 621).

Esse quadro de exclusão social compromete o argumento formulado pelos apoiadores dos governos autoritários ao defender, equivocadamente, que se vivia um período de prosperidade. $\mathrm{O}$ expressivo número de repetências e de evasóes também foi confirmado pelos entrevistados na pesquisa, uma vez que as dificuldades enfrentadas pelos moradores e por seus filhos contribuíam em demasia para afastá-los do ensino formal e de um maior acesso a empregos de melhor remuneração. Os relatos indicam, contudo, que a presença de servidores públicos como residentes na regiáo passou a ser ampliada a partir da implantação de algumas instituiçôes públicas na região, o que melhorou sua infraestrutura, contribuindo para atrair e fixar os moradores na região, muitos deles funcionários desses mesmos órgãos. A presença, no Conjunto, de servidores públicos como mutuários justifica-se pela demanda habitacional existente na cidade, além de que, embora as casas fossem destinadas a pessoas de baixa renda, o acesso a elas era dificultado por outros fatores, entre os quais, a comprovação de renda e o poder de endividamento daqueles que procuravam a Companhia de Habitação do estado.

Como ressalta Antonia Jesuíta de Lima (2010), os conjuntos habitacionais construídos durante a década de 1970 possuíam destinaçôes próprias, atendendo a determinados segmentos sociais definidos a partir do quesito de renda mínima. Toma-se, como exemplo, os conjuntos São Pedro, Saci, Cristo Rei, nos quais era exigida renda familiar acima de dois salários mínimos, e os conjuntos Parque Piauí e Bela Vista, que eram destinados a famílias com renda acima de um 
salário mínimo. Para o Conjunto Itararé, entretanto, era necessária a comprovação de renda familiar de até um salário mínimo, o que denota a destinação do residencial para famílias de baixíssima renda. ${ }^{11}$

Porém, a exigência de uma renda mínima também excluía o acesso àquelas famílias que não podiam comprovar rendimentos, fator importante em uma cidade com poucas oportunidades de emprego com registro de renda em carteira, como era o caso de Teresina, no período. Nesse sentido, a fala da senhora Maria do Amparo é elucidativa para entender o perfil dos moradores do Itararé:

A maioria das pessoas que vieram morar aqui, eram funcionários públicos, era policial, zelador, era o pessoal do hospital, mas essas casas foram praticamente para o pessoal que trabalhava no estado que ganhava pouco e não tinha condição de comprar um terreno para construir, e a opção foi essa. (Maria do Amparo, 2010).

Nela, a senhora Maria do Amparo destaca a expressiva presença de funcionários públicos entre os moradores no início do Conjunto, sobretudo os que passaram a trabalhar na região, nos primeiros órgãos de prestação de serviço como escolas públicas, Centro Social Urbano (CSU), posto de saúde e hospital - quando estes foram implantados no bairro. Confirmando que, além de construtor das residências e responsável pela distribuição, o poder público também se transformou em um dos principais geradores de emprego e renda para muitos dos habitantes do novo bairro, endossando o já declarado pela professora Inês Pereira.

Se, por um lado, esse relato confirma a destinação das casas para pessoas de baixa renda; por outro, mais uma vez, confirma a prioridade dada àqueles que podiam comprovar renda, condição também observada pela senhora Maria Neide, ao relembrar que "naquela época [1977] não vinha ninguém que não tivesse renda. Depois é que vieram pessoas que náo tinham renda fixa" (Maria Neide Fontineles, 2014). Dessa forma, a forte presença de funcionários públicos entre os primeiros moradores do Conjunto explica-se não por uma prioridade ou benefício oferecido pelo estado aos seus servidores, mas pela exclusão daqueles que não dispunham dos meios para demonstrar seus rendimentos pecuniários. O que, por sua vez, excluía significativa parcela daqueles a quem deveriam atender.

Assim, percebe-se que o critério de renda mínima foi exigido apenas para os primeiros grupos de moradores. Com a desistência e o abandono dessas casas em virtude das péssimas estruturas oferecidas pelo bairro, vastamente noticiadas nos periódicos locais entre as décadas de 1970 e 1980, esse critério passou a ser atenuado ou desconsiderado pelo poder público para distribuir as unidades habitacionais. Isso também pode ser notado no contrato assinado entre o estado e o $\mathrm{BNH}$, no qual consta que todos os custos com a construção do Itararé seriam arca-

11 O salário mínimo vigente a partir de maio de 1977, que era de Cr\$1.106,40 (hum mil, cento e seis cruzeiros e quarenta centavos). 
dos pelos seus moradores, por meio de mensalidades do financiamento imobiliário a serem pagas por eles. Essas mensalidades eram consideradas como a principal preocupação dos primeiros mutuários do Conjunto.

\section{Considerações Finais}

À medida que se pesquisava como foi planejada e implementada a construção do Conjunto Habitacional Itararé, foi-se observando como se deu o projeto estatal de retirada de famílias pobres das regióes urbanas, que despertava o interesse do capital especulativo imobiliário em relação às zonas leste e centro-sul de Teresina. Nesse sentido, foram construídas regras diferenciadas de inscrição nas novas residências, diversificando o perfil dos moradores desse residencial.

Ao analisar as fontes históricas, observamos que, durante a instalação dos moradores, foram sendo aplicadas regras distintas para a distribuição de unidades habitacionais no Conjunto, uma vez que a ausência de infraestrutura básica no início do residencial ocasionou um grande número de desistências entre os mutuários, assim como dificultou bastante a qualidade da vida daqueles que não dispunham de outra alternativa de moradia. Desta forma, a implantação dos serviços básicos foi fundamental para a fixaçáo dos primeiros moradores e para o desenvolvimento social das famílias, conforme os relatos orais dos entrevistados nesta pesquisa. A instalação desses serviços básicos também contribuiu para a fixação de alguns dos funcionários públicos como residentes da regiāo, diversificando o perfil dos moradores do Conjunto, embora continuasse a predominar o perfil de moradores com baixa renda.

A pesquisa possibilitou perceber como o projeto de ocupação desse bairro foi gestado e ganhou forma dentro da dinâmica histórica e social excludente de ocupação urbana que se apresentava à população de baixa renda nos anos de 1970. Ao discutir como os moradores enfrentaram as dificuldades que lhes foi apresentada em seu cotidiano, foi possível também analisar muitas das contradições vividas pela sociedade piauiense e brasileira durante o período autoritário e os mecanismos de adaptação/resistência, constituídos para fixar moradia mesmo diante de tais obstáculos.

\section{Referências}

ALBERTI. Verena. Ouvir contar: textos em História Oral. Rio de Janeiro: Editora FGV, 2010.

AMADO, Janaína. O Grande Mentiroso: tradição, veracidade e imaginação em 
História Oral. Revista História, São Paulo, v. 14, p. 125-136, 1995.

AMADO, Janaina; FERREIRA, Marieta de Moraes. Usos \& abusos da história oral. Rio de Janeiro: Editora FGV, 2006. 6. ed.

ARCOVERDE tem nome no Itararé. O Dia, Teresina, p. 1, 5 abr. 1979).

AUGUSTO, Carlos. Criação de Secretarias, O Dia, Teresina, p. 5, 23/24 mar. 1975.

BÉDARIDA, François. Tempo presente e a presença da história. In: AMADO, Janaina; FERREIRA, Marieta de Moraes. (Org.). Usos e abusos da história oral. Rio de Janeiro: Editora da FGV, 2006.

BENJAMIN, Walter. O narrador. Consideraçôes sobre a obra de Nikolai Leskov. In: BENJAMIN, Walter (Org.). Magia e técnica, arte e politica. Obras escolhidas. São Paulo: Brasiliense, 1987. 3. ed.

BLOCH, Marc. Apologia da História, ou, o ofício do historiador. Rio de Janeiro: Jorge Zahar Ed., 2001. p. 57.

BRASIL. BANCO NACIONAL DE HABITAÇÃO. Contrato de empréstimo entre o BNH e a COHAB-PI, com a interveniência do estado do Piauí [Projeto: Itararé. Objeto: 3040 casas]. Rio de Janeiro, 30 jun. 1976.

CAMARGO, Aspásia. Como a História Oral chegou ao Brasil: entrevista com Aspásia Camargo por Maria Celina d'Araújo. História Oral. Revista da Associação Brasileira de História Oral. São Paulo, n. 2, p. 167-179, jun. 1999.

CARLOS, Ana Fani Alessandri. O Espaço Urbano: novos escritos sobre a cidade. São Paulo: Contexto, 2001.

CERTEAU, Michel de; GIARD, Luce. Entremeio. In: CERTEAU, Michel de; GIARD, Luce; MAYOL, Pierre (Org.). A invençâo do cotidiano: 2. morar, cozinhar. Petrópolis, RJ: Vozes, 2005.

CORRÊA, Roberto Lobato. O espaço urbano. São Paulo: Ática, 2002.

CRIAÇÃO DE SECRETARIAS. O Dia, Teresina, p. V, 23/24 mar. 1975.

DELGADO, Lucília de Almeida Neves. História Oral: memória, tempo, identidade. Belo Horizonte: Autêntica, 2010.

DIRCEU visita os conjuntos e diz estar satisfeito, O Dia, Teresina, p. 3, 13 abr. 
1976.

DOSSE, François. História do Tempo Presente e Historiografia. Florianópolis, Revista Tempo \& Argumento, v. 4, n. 1, p. 5-22, 2012.

FERREIRA, Marieta de Moraes. História oral: velhas questóes, novos desafios. In: CARDOSO, Ciro Flamarion; VAINFAS, Ronaldo. (Orgs.). Novos dominios da história. Rio de Janeiro: Elsevier, 2012.

Refletindo sobre a profissão de historiador: entrevista a Mauro Dillmann e Francisco de Assis de Sousa Nascimento. Revista História Unisinos, v. 20, n. 1, p. 9-17, jan./abr. 2016.

ITARARÉ começa a receber seus ocupantes. O Dia, Teresina, p. 3, 2 jun. 1976.

ITARARÉ: uma cidade está se erguendo em Teresina. O Dia, Teresina, p. 16, 20 ago. 1977.

KOSSOY, Boris. Fotografia \& História. São Paulo: Ateliê Editorial, 2001.

LENINE. Envergo, mas não quebro. In: LENINE. Álbum: Chão. Gravadora Casa 9, 2011.

LIMA, Antonia Jesuíta. Favela COHEBE: uma história de luta por habitação popular. Teresina: EDUFPI; Recife: Bagaço, 2010.

LORENZETTI, Maria Sílvia Barros. A questão habitacional no Brasil. Brasília: Câmara dos Deputados [Estudo], 2001. Disponível em: <http://bd.camara.gov.br/ bd/handle/bdcamara/1469>. Acesso em: 16 set. 2014.

MELLO, João Manuel Cardoso de; NOVAIS, Fernando A. Capitalismo tardio e sociabilidade moderna. In: SCHWARCZ, Lilia Mortiz. História da vida privada no Brasil: contrastes da intimidade contemporânea, v. 4. São Paulo: Companhia das Letras, 2004.

MONTENEGRO, Antonio Torres. História e Memória: combates pela história. História Oral. Revista da Associação Brasileira de História Oral, São Paulo, v. 10, n. 1, p. 27-42, jan./jun. 2007. Disponível em: http://revista.historiaoral.org. $\mathrm{br} /$ index.php?journal $=$ rho\&page $=$ article\&op $=$ view \&path $\% 5 B \% 5 \mathrm{D}=206 \&$ path $\% 5 B \% 5 \mathrm{D}=210$. Acesso em: 15 out. 2015.

2001. 2. ed.

. História oral e memória: a cultura popular revisitada. São Paulo: Contexto, PESAVENTO, Sandra Jatahy. Cidades visíveis, cidades sensíveis, cidades imagi- 
narias. In: Revista Brasileira de História, São Paulo, v. 17, n. 53, julho de 2007.

PORTELLI, Alessandro. Ensaios de História Oral. São Paulo: Letra e voz, 2010.

. Sonhos ucrônicos: memórias e possíveis mundos dos trabalhadores. Projeto História. São Paulo, n. 10, dez. 1993.

PRINS, Gwyn. História Oral. In: BURKE, Peter (Org.). A escrita da História: novas perspectivas. São Paulo: Editora da Universidade Estadual Paulista, 1992.

RIOUX, Jean-Pierre. Pode-se fazer uma história do tempo presente?. In: CHAUVEAU, Agnes; TÉTART, Philippe (Org.). Questóes para a história do presente. Bauru: EDUSC, 1999.

ROLNIK, Raquel. O que é cidade. São Paulo: Brasiliense, 2004.

SILVA, Mariane Veloso da; FONTINELES, Claudia Cristina da Silva. As primeiras instituiçóes educacionais no Itararé durante a década de 1980: o que as fontes orais contam. Anais do XII Encontro Nacional de História Oral, p. 4. Teresina: UFPI, 2014. Disponível em: $<$ http://www.encontro2014.historiaoral.org.br/ resources/anais/8/1398900601_ARQUIVO_ArtigoMarianeClaudia2014XIIencontrodehistoral.pdf. $>$. Acesso em: 17 nov. 2014.

TOMPSON, Paul. A voz do passado: história oral. São Paulo: Paz e Terra, 2002. 3. ed.

VOLDMAN. Danièle. A invenção do depoimento oral. In: FERREIRA, Marieta de Moraes; AMADO, Janaína (Org.). Usos e abusos da História Oral. Rio de Janeiro: Editora da Fundação Getúlio Vargas, 2006.

\section{Fontes orais}

ALVES, Rosa Maria da Costa [84 anos]. [jul. 2017]. Entrevistadora: Cláudia Cristina da Silva Fontineles. Teresina, PI, 31 jul. 2017.

AMPARO, Maria do [56 anos]. [mar. 2010]. Entrevistadores: Verônica Viana de Sousa; Douglas de Farias Sousa. Teresina, PI, 15 mar. 2010.

CONCEIÇÃO, Maria da [50 anos]. [mar. 2010]. Entrevistadores: Verônica Viana de Sousa; Douglas de Farias Sousa. Teresina, PI, 1 mar. 2010.

DAMIÃO, Maria Dalva [60 anos]. [nov. 2017]. Entrevistadores: Marcelo de Sou- 
sa Neto; Cláudia Cristina da Silva Fontineles. Teresina, PI, 4 nov. 2017.

FONTINELES, Maria Neide da Silva [61 anos]. [dez. 2014]. Entrevistador: Marcelo de Sousa Neto. Teresina, PI, 17 dez. 2014.

PEREIRA, Maria Sancho [70 anos]. [dez. 2014]. Entrevistador: Marcelo de Sousa Neto. Demerval Lobão, PI, 28 dez. 2014.

SANTOS, Inês Pereira dos [65 anos]. [jun. 2013]. Entrevistadoras: Cláudia Cristina da Silva Fontineles; Mariane Vieira da Silva. Teresina, PI, 1 jun. 2013.

SILVA, Maria do Amparo Santos [57 anos]. [mar. 2010]. Entrevistadores: Verônica Viana de Sousa; Douglas de Farias Sousa. Teresina, PI, 1 mar. 2010.

Resumo: $\mathrm{O}$ presente artigo procura discutir como foi planejada e implantada a construção do Conjunto Habitacional Itararé - atualmente denominado de Dirceu Arcoverde -, o maior empreendimento no setor habitacional voltado à construção de moradias populares, no Piauí, da década de 1970. Essa região mantém-se como a mais populosa da capital piauiense desde entâo. Procuramos entender como esse projeto foi gestado e ganhou forma dentro da dinâmica histórica e social excludente que se apresentava à populaçáo de baixa renda no período. Discutimos como os desafios que se apresentaram ao cotidiano desses moradores se conectaram às contradiçóes vividas pela sociedade brasileira na década de 1970 - recorte temporal da pesquisa. Para tanto, recorremos à análise de fontes documentais e hemerográficas, com especial atenção aos registros fotográficos exibidos a respeito da regiâo nos jornais locais, além da adoção da metodologia da História Oral temática a partir de entrevistas com os primeiros moradores da regiáo.

Palavras-Chaves: História. Cidade. Memória. Moradia Popular. Teresina.

\section{Beyond the borders: the Itararé Popular Housing and the urban renewals in Teresina (1970's decade)}

Abstract: This paper aims to address how the Itararé Housing Estate - currently called Dirceu Arcoverde - construction was planned and implemented. It was the largest housing development project in the 1970s in Piauí, and the region with the largest population region in the capital of Piaui since then. We aimed to understand how this project was managed and took shape within the exclusionary historical and social dynamics presented to the low-income population in the period. We discuss how the challenges faced daily by these residents were connected to the contradictions experienced by Brazilian society in the 1970s - time frame of the research. Therefore, we resorted to the analysis of documentary and hemerographic sources, specially concerning the photographic records 
about the region displayed in local newspapers. Furthermore, we adopted the thematic Oral History methodology through interviews with the first residents of the region.

Keywords: History. City. Memory. Popular Housing. Teresina.

Recebido em 16/08/19

Aprovado em 10/10/19 